DOI: 10.1515/ausfm-2015-0027

\title{
The World of The Walking Dead - Transmediality and Transmedial Intermediality
}

\author{
Benjamin Beil, Hanns Christian Schmidt \\ University of Cologne (Germany) \\ E-mails: benjamin.beil@uni-koeln.de, schmidt.c@uni-koeln.de
}

\begin{abstract}
As transmedia franchises increasingly populate our cultural environment, many questions arise about the effect of the different media involved in the depiction of storyworlds. Through the analysis of different examples, with special emphasis on the particular case of The Walking Dead, and drawing primarily from Henry Jenkins's concept of "transmedia storytelling" and Jens Schröter's concept of intermediality, this paper aims to show how different media aesthetics contribute to the process of storytelling and enrich the experience of the consumer. Usually overlooked in other analyses, we argue that these formal and aesthetical characteristics, such as the interactive nature of video games, call for a broader approach that transcends the accustomed search of common narrative aspects. This will be exemplified by a closer comparative look at the adventure game The Walking Dead: The Game (Telltale Games, 2012) and The Walking Dead: Survival Instinct (Terminal Reality, 2013). The transformations that the different media demand contribute not only to the narrative, but also provide different tools for the construction of storyworlds and different ways to engage with it.
\end{abstract}

Keywords: computer games, intermediality, transmedia storytelling, storyworlds, The Walking Dead.

In the course of digital media change, contemporary media franchises are increasingly becoming transmedial phenomena, exceeding the limits of their own media dispositifs. Films, television series, comic books or video games migrate to other media platforms and enrich their narratives through transmedial extensions (cf. Jenkins 2006; Evans 2011; Mittel 2012; Smith 2009; Askwith 2007; Dena 2009).

From a media-economical perspective, this development can simply be seen as a franchise strategy within multi-media value-added chains (cf. Brookey 2010; Hardy 2011; Johnson 2013). However, a media-aesthetic approach shows that the efforts to create a "harmonic" digital media convergence (Jenkins 2006) remain 
questionable. In this paper, we will argue that many transmediality theories most notably Jenkins's widely discussed convergence culture approach - have an "intermedial blind spot" because they reduce transmedia storytelling to a search for narrative fragments spread across different media platforms. Still, such a strategy would ultimately reduce transmedial extensions to their narrative aspects.

Using Jens Schröter's theory of intermediality and his concept of formal or transmedial intermediality (Schröter 2011), we will demonstrate that an analysis of transmedia storytelling techniques requires an intermedial perspective, which emphasizes different media aesthetics (i.e. the interactive nature of video games).

After some (more general) remarks about contemporary adaptation strategies and convergence culture, we will illustrate this approach by taking a closer look at one of the most successful contemporary transmedia franchises, The Walking Dead, especially concerning two recent video game adaptations: an adventure game (The Walking Dead, Telltale, 2012) and a first-person shooter (The Walking Dead: Survival Instinct, Activision, 2013). Our analysis will show the complex intermedial connections and transformations between the different transmedial extensions, which contribute not only to a larger transmedia narrative but also to the construction of a compelling storyworld expanding across media. In this regard, we also present an explanation on why the Walking Dead adventure game has received so much critical praise, whereas the first-person shooter is widely regarded as a generic (i.e. failed) adaptation.

\section{Haunted House Rides and M56 - The Videogame}

A frequently cited example of media convergence between video games and films is the movie Doom (Andrzej Bartkowiak, 2005), an adaptation of Doom 3 (id Software, 2004), the sequel of the video game classic Doom (id Software) from 1993 which marks a milestone in the evolution of the first-person shooter genre. From an aesthetic perspective, the most interesting part of Doom is a fiveminute sequence shot occurring near the end of the film which uses a subjective camera, whereas all previous scenes are realized with "classical" framing and montage techniques. ${ }^{1}$ The subjective camera shows the view of the protagonist, space marine John Grimm, who is fighting hordes of demons and zombies on his

1 We use the term "classical" at this point and in the following basically in the sense of a Classical Hollywood Cinema (Bordwell, Staiger and Thompson 1985). Although (short) point of view shots are part of this visual repertoire, early experiments like Lady in the Lake (Robert Montgomery, 1947) or Dark Passage (Delmer Daves, 1947) failed to establish (longer) subjective camera sequences as a classical technique. 
way through the corridors of a space station. At first glance, this sequence seems quite "faithful" to the visual style of its (gamic) source material: the protagonist's weapon is positioned in the lower third of the picture (yet the head-up display elements of the game are missing) [Figs. 1-2].

However, at second glance, the use of subjective camera turns out to have much more in common with stylistic devices of the (filmic) horror genre (cf. Neale 1984; Clover 1994) - or rather with cheap scares caused by objects (like genretypical demons and zombies) rapidly moving towards the camera. However, this mainly affective style ${ }^{2}$ of the subjective camera becomes quite artificial in a longer sequence. In other words: The first-person sequence in Doom might work as an homage to Doom 3 (or rather to the first-person shooter genre in general), but, ultimately, this five-minute shot sequence is more reminiscent of a haunted house ride at the fair than a first-person shooter experience.

But what is the reason for this problematic status of the subjective camera in Doom? The enormous success of the first-person perspective in video games is quite easy to explain: the first-person view is the ideal form of representation for shooting-gameplay mechanics - and, in this respect, it seems only logical (or even "natural") that in most first-person shooters the movement of the weapon is usually (but rather "unnaturally") tied to the view of the avatar. Rune Klevjer speaks aptly of a "camera-gun" (Klevjer 2006). In film, this game-mechanical reason is missing, so the subjective camera, which can function as a reference to video games, does not create a sort of filmic video game aesthetics. In most cases, the use of the subjective camera simply means a reduction of the film's stylistic devices, especially montage-techniques. Therefore, it is usually ${ }^{3}$ only used as a short spectacular interplay (cf. Moreno 1953; Metz 1973; Mitry 1998).

Doom (the game) is also quite often cited as an example of the influence of films on video game culture, and vice versa. The game is described as an (unofficial)

2 Using the example of Strange Days (Kathryn Bigelow, 1995), Steven Shaviro argues that the subjective camera is "all speed, violence, and nervous tension" (Shaviro 2001, 61). "The subjective camera doesn’t just look at a scene. It moves actively through space. It gets jostled, stops and starts, it pans and tilts, it lurches forward and back. It follows the rhythms of the whole body, not just that of the eyes. This is a presubjective, affective and not cognitive, regime of vision" (Shaviro 2001, 62).

3 There are very few examples to prove the opposite - i.e. The Diving Bell and the Butterfly (Le scaphandre et le papillon, Julian Schnabel, 2007), a movie which starts with an impressive 45-minute first-person sequence. But because of its rather special protagonist - a completely paralysed man who suffers from the so called locked-in syndrome - the film stays a peculiarity. Further exceptions are "video diaries" like Blair Witch Project (Daniel Myrick and Eduardo Sánchez, 1999) or Cloverfield (Matt Reeves, 2008), but these films also feature quite unusual scenarios. 
adaptation of James Cameron's sci-fi classic Aliens (1986), or rather as a strange hybrid of Aliens and The Evil Dead II (Sam Raimi, 1987) - as David Kushner explains in his production notes Masters of Doom: "Everyone at id was a huge fan of this sci-fi movie. They thought it would make a great game. After some research, Jay [Wilbour] found that the rights were available. He thought they could get a deal. But then they decided against it. [...] Here was this amazing new technology, so why not have a game about demons versus technology, Carmack said, where the player is using high-tech weapons to defeat beasts from hell? [...] They all agreed that was what the game could be like: a cross between Evil Dead and Aliens, horror and hell, blood and science" (Kushner 2004, 122-123) [Figs. 3-4].

On closer inspection, even the "hybrid theory" seems to be too broad. As Matteo Bittanti (2008) argues, John Carmack and John Romero, the famous co-founders of id Software, were not really interested in a typical adaptation of Aliens (the film's story, setting, etc.; cf. Stam 2005), but were rather fascinated by certain audiovisual details, especially Cameron's dramatic staging of weapons: "John Carmack and John Romero's re-writing of Aliens is not faithful to its source, as Cameron's movie centres on a female character fighting against hordes of phallic-shaped monsters. Rather, they adapted the M56 smart gun itself' (our emphasis, Bittanti 2008).

\section{Convergence Culture?}

At first glance, contemporary video game and film cultures seem to be closely intertwined. Game developers promote their works as "filmic games" (Nutt 2008) or "cinematic experience" (Davis 2010), certain sequences are described as "cinematic set pieces" (Graft 2009) or "blockbuster moments" (Graft 2009). The numerous links between these two media systems are also currently highlighted by over a hundred films based on video games, ${ }^{4}$ as well as countless game adaptations of blockbuster movies.

But, at second glance, such a "harmonic" media convergence between video games and films (cf. Jenkins 2006, 95-134) seems questionable. On the one hand, in film studies the term "video game aesthetic" is quite often used to describe typical Hollywood summer blockbusters with spectacular effects and generic stories. On the other hand, game studies scholars normally praise a "cinematic experience" of a video game - and then also criticize its generic story (as well as its simplistic gameplay).

4 Cf. List of Films Based on Video Games: http://en.wikipedia.org/wiki/List_of_films_based_on_ video_games. Last accessed 18. 02. 2015. 
Video game adaptations of (blockbuster) movies especially enjoy a rather dubious reputation because they are often quickly-produced tie-in games. ${ }^{5}$ The developers are under pressure to finish the game in time for the film's release, and therefore these games are usually not very faithful adaptations, but rather mediocre genre clones which only use the movie plot (or certain story fragments, characters and locations) as a narrative background. ${ }^{6}$ In this way, the convergence between video game and film cultures presents itself more as a close connection between game and film industries, a franchise strategy in multi-media valueadded chains (cf. Brookey 2010).

So, what does this mean for an intermedia comparison? Without question, video games have had a huge influence on films, and vice versa (cf. King and Krzywinska 2002; Bittanti 2001). But a term like "video game aesthetics" seems to be highly problematic because it remains extremely vague. Alexander Galloway (2006) argues that most approaches that deal with cinematic games or gamic cinema are far too diffuse. There is no typical cinematic video game and a video game does not become a cinematic experience by integrating filmic (but non-interactive!) cutscenes, e.g. the Wing Commander series (Origin Systems, 1990-1996) (cf. Hancock 2002; Klevjer 2002; Lunenfeld 2004). In the same way, a film does not become a gamic experience by taking place in a video game world (e.g. Rich Moore's Wreck-It Ralph, 2012). ${ }^{7}$

Of course, one can find similar audiovisual styles in films and video games as Galloway (2006) demonstrates in his revealing comparison between the subjective camera and the first-person (shooter) perspective. Against this background, the subjective camera in Doom must be seen as part of a long and complex history of intermedial interactions between photography, cinema, television and gaming. In other words: although the subjective camera can function as a reference to firstperson video games, its aesthetic qualities are usually much more complex - or much more problematic.

$5 \quad$ This "tie-in reputation" seems to apply all the more for superhero game franchises, e.g. the "infamous" Marvel-Sega collaboration which resulted in flawed games like Iron Man (Secret Level, 2008), Thor: God of Thunder (Liquid Entertainment, 2011), and Captain America: Super Soldier (Next Level Games, 2011).

6 There is a beat-'em-up (The Lord of the Rings: The Two Towers [Stormfront Studios, 2002]), a real-time strategy (The Lord of the Rings: The Battle for Middle-Earth [Electronic Arts, 2004]) and an online-RPG (The Lord of The Rings Online [Turbine, 2007]) version of the Lord of the Rings movies (Peter Jackson, 2001-2003).

$7 \quad$ Matteo Bittanti speaks aptly of gamexploitation: "The logic behind the adaptation strategy is purely economic: In most cases, these films simply try to draw a pre-existing fan base to the cinema rather than expanding the cinematic discourse on video games" (Bittanti 2001, 208). 
To argue with Jens Schröter's theory of intermediality: a comparison between a video game and a film (television series, comic, etc.) should not - or at least not predominantly - focus on narrative props, like certain characters, locations, or items. The essential category is rather a formal or transmedial intermediality, by which Schröter means: "a concept based on formal structures not 'specific' to one medium but found in different media" (Schröter 2011, 2), like for example fictionality, rhythmicity, immersiveness, or seriality. "These concepts and principles are separated from the material basis of the media, thus, they can be seen as relatively autonomous - and in this sense they are transmedial, although they can only actualize within a media substratum” (Schröter 2011, 2). Or, as Joachim Paech puts it: "there is no intermediality between literature and film; there is one only between media narrating literarily or cinematically" (Paech 1997, 335).

\section{The Walking Dead as an Example of a Transmedial World}

Considering the various and sometimes problematic intermedial connections between films and videogames in Paech's sense, it might seem rather unnecessary to put even more methodological variables into the equation. However, another concept comes to mind when those texts are considered as "officially licensed" formats within a fictional narrative universe which is dispersed across different media channels. To make sense of the various levels of production, distribution and reception at play, scholars like Marsha Kinder (1994), Mary Celeste Kearny (2004) or - maybe most prominently - Henry Jenkins (2006) focused on the term transmediality instead of intermediality. While Kinder and Kearny offered insights from a sociological perspective and highlighted possible media effects these phenomena might have on children and adolescents, Henry Jenkins gained significant attention from scholars (and business insiders) when he connected the term transmediality to the realm of storytelling. With this emphasis on a narrative outcome, he also stressed the aesthetic pleasures fans have when engaging in such media franchises. In an updated version, Jenkins (2007) defines transmedia storytelling as "a process where integral elements of a fiction get dispersed systematically across multiple delivery channels for the purpose of creating a unified and

8 Cf. Schröter once again: "Although these terms do not function on the same level, they nevertheless share a common ground in that they have already all been used in order to compare artifacts made from different media on a more abstract level" (Schröter 2011, 3). 
coordinated entertainment experience. Ideally, each medium makes its own unique contribution to the unfolding of the story."

The recognition and influence that Jenkins's idea received is undeniable, but attempts to connect it to already existing theoretical fields have proven to be problematic. In this sense, scholars like David Bordwell or MarieLaure Ryan argue against the cogency of such a concept mainly because of its delicate impact on the aesthetics of reception (especially concerning framing and sequencing of a narrative across media [cf. Bordwell 2009]) and messy links to narrative theory (e.g. regarding concepts of transfictional storyworlds and authorship [cf. Ryan 2013a]). Quite ironically, the criticism towards the concept of transmedia storytelling has initiated a fruitful discussion between Jenkins and other scholars, which eventually played out across media as well, employing blogs or recorded forum discussions on YouTube. ${ }^{9}$ In these appearances, Jenkins highlighted not only a notion of work in progress due to the challenges of a constantly changing media environment (Ryan 2013b) but also emphasized a different perspective on his work (Jenkins 2009). In the already mentioned discussion with David Bordwell, he pointed out that "good transmedia works" were not so much concerned with constructing an ongoing plot or an arc of suspense across different media channels, but would rather embrace two "aesthetic impulses" (Jenkins 2009). These impulses Jenkins called "world building and seriality" (Jenkins 2009).

In this sense, Schröter's concept of "transmedia intermediality" as "formal structures, not specific to one medium but found in different media" (Schröter 2011) can been seen as a (quite literal) approach to the concept of seriality. This might even offer new insights enhancing Jenkins's model: by focusing on the academic discourse of TV-series, one could argue with Jeffrey Sconce (2004) that "U.S. television has devoted increased attention in the past two decades to crafting and maintaining ever more complex narrative universes, a form of 'world building' that has allowed for a wholly new mode of narration and that suggests new forms of audience engagement. Television, it might be said, has discovered that the cultivation of its story worlds (diegesis) is as crucial an element in its success as is storytelling. What television lacks in spectacle and narrative constraints, it makes up for in depth and duration of character relations, diegetic expansion, and audience investment" (Sconce 2006).

9 See, for example, both Jenkins's and Bordwell's weblog and the recorded and uploaded discussion after Marie-Laure Ryan's keynote speech on the Rethinking Intermediality Conference this volume is based on, cf. Ryan 2013. 
The idea of world building in TV-series which create "ever more complex narrative universes" due to their use of a vast array of narrative time (what Horace Newcomb [2004] calls "cumulative narrative") sounds compelling. In the context of transmediality however, it still leaves one important question unanswered: how can transmedia extensions contribute to narratives which already function well in a single medium - and, respectively, build a world successfully on their own?

Even if the question of how certain media might deliver an "integral" or "unique" contribution "to the unfolding of a story" in Jenkins's sense (2007) remains very broad, one might still assume that digital games offer a certain level of involvement and agency, which is usually not expected from non-interactive media like literature, film or television shows. Judging from the sheer quantity of licensed games (so-called tie-in games), these possibilities have already been acknowledged by the creative industries a long time ago.$^{10}$ However, most of these "adaptations" are mini game compilations (usually for mobile gaming platforms like the iPhone or android devices) or low budget genre-clones (e.g. all twelve [!] game adaptations of CSI are very simple point-and-click adventures) which seem to disappoint fans on a regular basis, because these tend to expect a product of quality comparable to that of the source material (cf. Evans 2011, 107 and Mittell 2012).

One recent, more ambitious exception is the The Walking Dead-franchise, in which various media formats seem to encapsulate Jenkins's idea of seriality and world building to construct a compelling overall transmedia universe. While the narrative framework of both the original comic books and the adapted TV-series (which function as core texts with various transmedia extensions independently from each other) is not really original in terms of characters or setting, it is rather the formal aspect of seriality itself which determines its key characteristic. As in the comics and the TV-series, the protagonist Rick Grimes encounters many situations the audience is already familiar with from dozens of films from the same genre. But instead of only ripping off those genre predecessors (which usually stop at about two hours of screen time because all the people are either rescued or killed), The Walking Dead's main character is forced to continue with his ongoing struggle to survive on a long-term basis due to the logic of serial narration. This is the reason why Rick Grimes appears to be literally a hero (or

10 A small selection of tie-in games with very uninspired names: CSI: Crime City (Ubisoft, 2010), Dexter: The Game (Icarus Studios, 2009), House M.D.: The Game (Legacy Games, 2009), Grey's Anatomy: The Video Game (Ubisoft, 2009), 24: The Game (SCE Studio, 2006), Heroes: The Mobile Game (Gameloft, 2007), The Simpsons Game (Electronic Arts, 2007), Family Guy Video Game! (High Voltage Software, 2006), Battlestar Galactica Online (Bigpoint, 2011), Doctor Who: The Adventure Games (Sumo Digital, 2010-2011). 
rather a victim) of cumulative narration in Newcomb's sense: in the first 1088 pages of the comics, Rick does not only lose one of his limbs (his right hand, to be more precise) but also all of his community members, his wife, his newly born daughter and - albeit temporarily - his mind.

When The Walking Dead is considered a franchise that expands its storyworld(s) across media, it is interesting to focus on two videogames that take place in the original setting: the self-titled adventure game The Walking Dead: The Game (Telltale Games 2012, licensed for the comics) and the first person shooter The Walking Dead: Survival Instinct (Terminal Reality 2013, licensed for the TV-series). Arguing from a narrative perspective, both games function as prequels to their individual core text and present new narrative information about the setting and some background information to already known characters from the series and the comic. Thus, they seem to provide a contribution to the storyworld as a whole and therefore appear to fit into Jenkins's aforementioned concept of transmedia storytelling. But, strikingly, the reception of the games could not have been more diverse: while the adventure game was enormously praised by numerous critics and received over 90 (!) "Game of the Year"-awards, the first-person-shooter was described as "painfully dull" (McInnis 2013) and as "the exact sort of lazy, cheap cash-grab that gave licensed games a bad name in the first place" (McElroy 2013). While it is hard to ignore the fact that The Walking Dead: Survival Instinct indeed seems to be a pretty bad game mainly due to its repetitive and clumsy gameplay-mechanics [Fig. 5], ${ }^{11}$ it is worth mentioning that the adventure game on the other hand decreased most gameplay-mechanics to a minimum. Instead, it made use of many of the implicit features of its core text's storyworld.

Regarding the question of how to trace these implicit features, it is useful to take Lisbeth Klastrup's and Susana Tosca's model of a “transmedial world” (2004) into account. At first glance, both games seem to be consistent with their original core text: taking place in the US-state of Georgia under 'zombie-apocalyptic' circumstances, the setting (which Klastrup and Tosca call topos of a transmedial world) and the backstory (which they call the mythos) from the comics and TV-show can easily be recognized in the games. But while the shooter mainly reproduces the act of killing zombies in a quite tiresome way, it completely misses the overall emotional tones which are constituted by the character-driven

11 While some may argue that there is an interesting narrative framework in the game, the overall experience suffers from the actual way it is played: basically, all the player has to do is to drive around until they run out of gas, make a stop to collect some fuel and other goods and to kill some zombies on the way - only to repeat the whole process over and over again. 
serialized original. Opposed to this, the adventure game stays rather faithful to a certain "spirit," "emotional core" (Caldwell 2003, 138) or, as Klastrup and Tosca put it, the ethos of the original, which they define as "explicit and implicit ethics of the world and (moral) codex of behaviour, which characters in the world are supposed to follow" (Klastrup and Tosca 2004). In contradistinction to the shooter, the adventure game mainly focuses on the slow development of characters in a rather sophisticated dramatic story arc, lasting five successive episodes, which were released within the time period of almost a year. In these installments, the player takes over the role of a former history teacher (and convicted murderer) who stumbles upon a little girl during the first hours of the apocalypse. The girl, who is looking for her parents, quickly becomes the protégé of the player. While looking for a safe place, the player assumes the role of a father figure, with numerous opportunities to care selflessly for the girl and prepare her for the dangers of the savage world outside [Fig. 6] - until he ultimately ends up bitten by a zombie in the second to last episode of the game, facing certain death and having to release the girl from his protection.

While this coming-of-age/father-and-daughter story with a zombie-twist is a rather unusual one for a commercially successful videogame, its melodramatic tone is even enhanced by its gameplay. By confronting the player with certain key situations in which he has to decide on a narrative outcome, the game creates an individual story experience and the illusion of choice. While basic plot points of the game's narrative are predetermined and therefore unchangeable by the player, his virtual in-game-companions constantly keep record of his actions, change their attitude towards him and will remind and sometimes even punish him for his behavior. In this regard, the game creates the impression that the player's actions have an impact on the mind-set of the other non-playable characters. Judging from critical and user reactions towards the game,,$^{12}$ this aspect is most successfully exploited by the character of the player's protégé, the little girl Clementine. She acts like a moral compass, questioning the player's decisions throughout the whole game from the perspective of an eight-year-old and showing either signs of affection or disappointment.

By combining a rather mature story with an unhappy ending and the possibility to add some personalized shades to the narrative, The Walking Dead's adventure

12 Regarding the emotional involvement of the game, the micro-blogging platform Tumblr was used as a kind of reservoir for short player impressions of the game. Particularly interesting in context of player-reactions is the so-called Confessions-Tumblr, to which players of the game were invited to contribute: cf. http://thewalkingdeadgameconfessions.tumblr.com/. Last accessed 18. 02. 2015. 
game stands out as a quite unconventional (and successful) licensed digital game. The first-person-shooter on the other hand may be regarded as an uninspired generic example in the realm of tie-in-merchandise. However, when the two games are tackled as case studies for a set of inter- and transmedial theories, we can clearly recognize the "transmedial blind spot" of Jenkins's first draft in his "transmedia storytelling"-concept. This is most apparent in regard to his former focus on narrative information. This short analysis showed that formal structures - in this case seriality and innovative gameplay mechanics - need to be taken into theoretical account as well (cf. Schröter's theory of "transmedial intermediality"). They seem to be, after all, the reason why an expansion of a transmedial world may be regarded as accepted or rejected by its audience. In the case of the two games, the implicit qualities of the story world, which Klastrup and Tosca called the ethos of the transmedial world, are not only kept intact in the adventure game, but are even exceeded in terms of emotional involvement. Opposed to the shooter, which remains basically a stimulus-response-test with zombies, the adventure game not only stays faithful to the original source, but, moreover, builds a compelling part of a greater transmedial world.

\section{References}

Askwith, Ivan. 2007. Television 2.0. Reconceptualizing TV as an Engagement Medium. M.Sc. thesis, MIT. http://cms.mit.edu/research/theses/IvanAskwith 2007.pdf. Last accessed 18. 02. 2015.

Bittanti, Matteo. 2001. The Technoludic Film. Images of Video Games in Movies (1973-2001). PhD dissertation, San Jose State University.

Bittanti, Matteo. 2008. From Gunplay to GunPorn: A Technovisual History of the First-Person Shooter. http://humanitieslab.stanford.edu/44/249. Last accessed 01. 03. 2014.

Bordwell, David, Janet Staiger and Kristin Thompson. 1985. The Classical Hollywood Cinema: Film Style and Mode of Production to 1960. New York: Columbia University Press.

Bordwell, David. 2009. Now Leaving from Platform 1. http://www.davidbordwell. net/blog/2009/08/19/now-leaving-from-platform-1/. Last accessed 18. 02. 2015.

Brookey, Robert Alan. 2010. Hollywood Gamers. Digital Convergence in the Film and Video Game Industries. Bloomington: Indiana University Press. 
Caldwell, John T. 2003. Second Shift Media Aesthetics. Programming, Interactivity and User Flows. In New Media: Theories and Practices of Digitextuality, eds. John T. Caldwell and Anna Everetts, 127-144. New York: Routledge.

Clover, Carol J. 1994. The Eye of Horror. In Viewing Positions: Ways of Seeing Film, ed. Linda Williams, 184-230. New Brunswick: Rutgers University Press.

Davis, Ashley. 2010. Creating the Cinematic Experience of Uncharted 2. http://www.destructoid.com/gdc-10-creating-the-cinematic-experience-ofuncharted-2-166867.phtml. Last accessed 18. 02. 2015.

Dena, Christy. 2009. Transmedia Practice: Theorising the Practice of Expressing a Fictional World Across Distinct Media and Environments. PhD dissertation, University of Sydney.

Evans, Elizabeth. 2011. Transmedia Television. Audiences, New Media and Daily Life. New York: Routledge.

Galloway, Alexander R. 2006. Origins of the First-Person Shooter. In Gaming. Essays on Algorithmic Culture, ed. Alexander R. Galloway, 39-69. Minneapolis, London: University of Minnesota Press.

Graft, Kris. 2009. Reflecting on Uncharted 2. How They Did It. http://www. gamasutra.com/view/feature/4191/reflecting_on_uncharted_2_how_php. Last accessed 01. 03. 2014.

Hancock, Hugh. 2002. Better Game Design Through Cutscenes. http://www. gamasutra.com/view/feature/131410/better_game_design_through_php. Last accessed 01. 03. 2014.

Hardy, Jonathan. 2011. Mapping Commercial Intertextuality. HBO's True Blood. Convergence: The International Journal of Research into New Media Technologies no. 17: 7-17.

Jenkins, Henry. 2006. Convergence Culture: Where Old and New Media Collide. New York: New York University Press.

Jenkins, Henry. 2009. The Aesthetics of Transmedia: In Response to David Bordwell (Part Two) http://henryjenkins.org/2009/09/the_aesthetics_of_ transmedia_i_1.html\#sthash.7aSqSya3.dpuf. Last accessed 18. 02. 2015.

Jenkins, Henry. 2007. Transmedia 101: Further Reflections. http://henryjenkins. org/2007/03/transmedia_storytelling_101.html. Last accessed 18. 02. 2015.

Johnson, Derek. 2013. Media Franchising. Creative License and Collaboration in the Culture Industries. New York: New York University Press.

King, Geoff and Tanya Krzywinska, eds. 2002. ScreenPlay: Cinema/Videogames/ Interfaces. London: Wallflower Press. 
Klastrup, Lisbeth and Susana Tosca. 2004. Transmedial Worlds: Rethinking Cyberworld Design. http://www.cs.uu.nl/docs/vakken/vw/literature/04. klastruptosca_transworlds.pdf. Last accessed 18. 02. 2015.

Kearny, Mary Celeste. 2004. Recycling Judy and Corliss: Transmedia Exploitation and the First Teen-Girl Production Trend. Feminist Media Studies vol. 4 no. 3: 265-295.

Kinder, Marsha. 1991. Playing with Power in Movies, Television, and Video Games: From Muppet Babies to Teenage Mutant Ninja Turtles. Berkeley: University of California Press.

Klevjer, Rune. 2002. In Defense of Cutscenes. http://folk.uib.no/smkrk/docs/ klevjerpaper.htm. Last accessed 18. 02. 2015.

Klevjer, Rune. 2006. The Way of the Gun: The Aesthetic of the Single-Player First Person Shooter. http://www.uib.no/People/smkrk/docs/wayofthegun.htm. Last accessed 18. 02. 2015.

Krzywinska, Tanya. 2002. Hands on Horror. In ScreenPlay: Cinema/Videogames/ Interfaces, eds. Geoff King and Tanya Krzywinska, 206-223. London: Wallflower Press.

Kushner, David. 2004. Masters of Doom. How Two Guys Created an Empire and Transformed Pop Culture. London: Piatkus.

Lunenfeld, Peter. 2004. The Myths of Interactive Cinema. In Narrative Across Media: The Languages of Storytelling, ed. Marie-Laure Ryan, 377-390. Lincoln: University of Nebraska Press.

McElroy,Justin.2013.TheWalkingDead:SurvivalInstinctReview.HumanSuffering. http://www.polygon.com/2013/3/19/4125248/the-walking-dead-survivalinstinct-review. Last accessed 18. 02. 2015.

McInnis, Shaun. 2013. The Walking Dead: Survival Instinct Review. http://www.gamespot.com/reviews/the-walking-dead-survival-instinctreview/1900-6405891/. Last accessed 18. 02. 2015.

Metz, Christian. 1973. Current Problems of Film Theory. Screen no. 14: 40-87.

Mitry, Jean. 1998 [1963-1965]. The Aesthetics and Psychology of the Cinema. London: Athlone Press.

Mittell, Jason. 2012. Complex TV. The Poetics of Contemporary Television Storytelling. http://mediacommons.futureofthebook.org/mcpress/complex television. Last accessed 18. 02. 2015.

Moreno, Julio L. 1953. Subjective Cinema and the Problem of Film in the First Person. The Quarterly of Film Radio and Television vol. 7 no. 4: 341-358. 
Neale, Steve. 1984. Halloween. Suspense, Aggression and the Look. In Planks of Reason. Essays on the Horror Film, ed. Barry Keith Grant, 65-78. Metuchen: Scarecrow Press.

Newcomb, Horace. 2004. Narrative and Genre. In The Sage Handbook of Media Studies, eds. John Downing, Denis McQuail, Philip Schlesinger and Ellen Wartella, 421-423. Thousand Oaks (CA), London and New Delhi: Sage.

Nutt, Christian. 2008. Designing Filmic Games. Paul O'Connor and The Bourne Conspiracy. http://www.gamasutra.com/view/feature/3577/designing_filmic_ games_paul_.php. Last accessed 18. 02. 2015.

Ryan, Marie-Laure. 2013a. Transmedial Storytelling and Transfictionality. http:// users.frii.com/mlryan/transmedia.html. Last accessed 18. 02. 2015.

Ryan, Marie-Laure. 2013b. Transmedia Storytelling: Myth or Reality? http://www. youtube.com/watch?v=zqFsg8zqcLA. Last accessed 18. 02. 2015.

Paech, Joachim. 1997. Paradoxien der Auflösung und Intermedialität [Paradoxes of Resolution and Intermediality]. In HyperKult. Geschichte, Theorie und Kontext digitaler Medien [HyperKult. History, Theory and Context of Digital Media], eds. Martin Warnke, Wolfgang Coy and Georg Christoph Tholen, 331368. Basel: Stroemfeld.

Schröter, Jens. 2011. Discourses and Models of Intermediality. CLCWeb: Comparative Literature and Culture vol. 13 no. 3: 1-7.

Sconce, Jeffrey. 2006. What If? Charting Television's New Textual Boundaries. In Television After TV. Essays on a Medium in Transition, eds. Lynn Spigel and Jan Olsson, 92-112. Durham: Duke University Press.

Shaviro, Steven. 2001. Regimes of Vision. Kathryn Bigelow, Strange Days. Polygraph 13: 59-68.

Smith, Aaron. 2009. Transmedia Storytelling in Television 2.0. Strategies for Developing Television Narratives Across Media Platforms. B.A. thesis, Middlebury College. http://sites.middlebury.edu/mediacp/files/2009/06/ Aaron_Smith_2009.pdf. Last accessed 18. 02. 2015.

Stam, Robert. 2005. Literature Through Film: Realism, Magic, and the Art of Adaptation. Malden, Massachusetts: Blackwell. 


\section{List of Figures}

Figures 1-2. The movie Doom (2005) and the video game Doom 3 (2004).
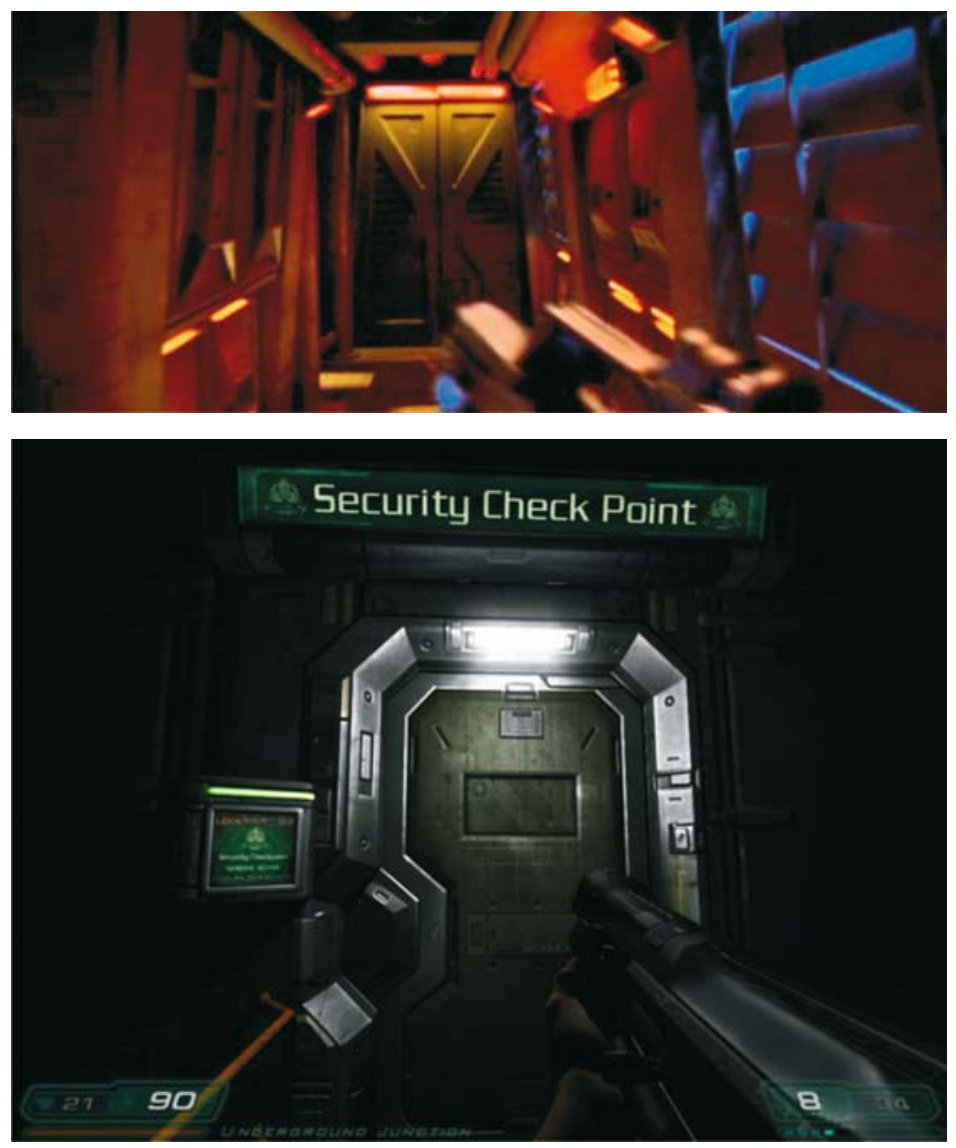

Figures 3-4. Aliens (1986) and Doom (1993; cover art, detail).
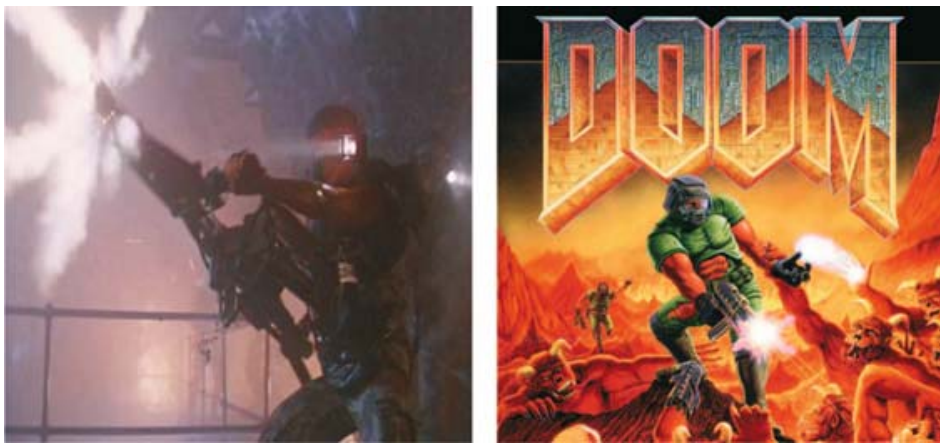
Figures 5-6. Gameplay of The Walking Dead: Survival Instinct (2013) and The Walking Dead: The Game (2012).
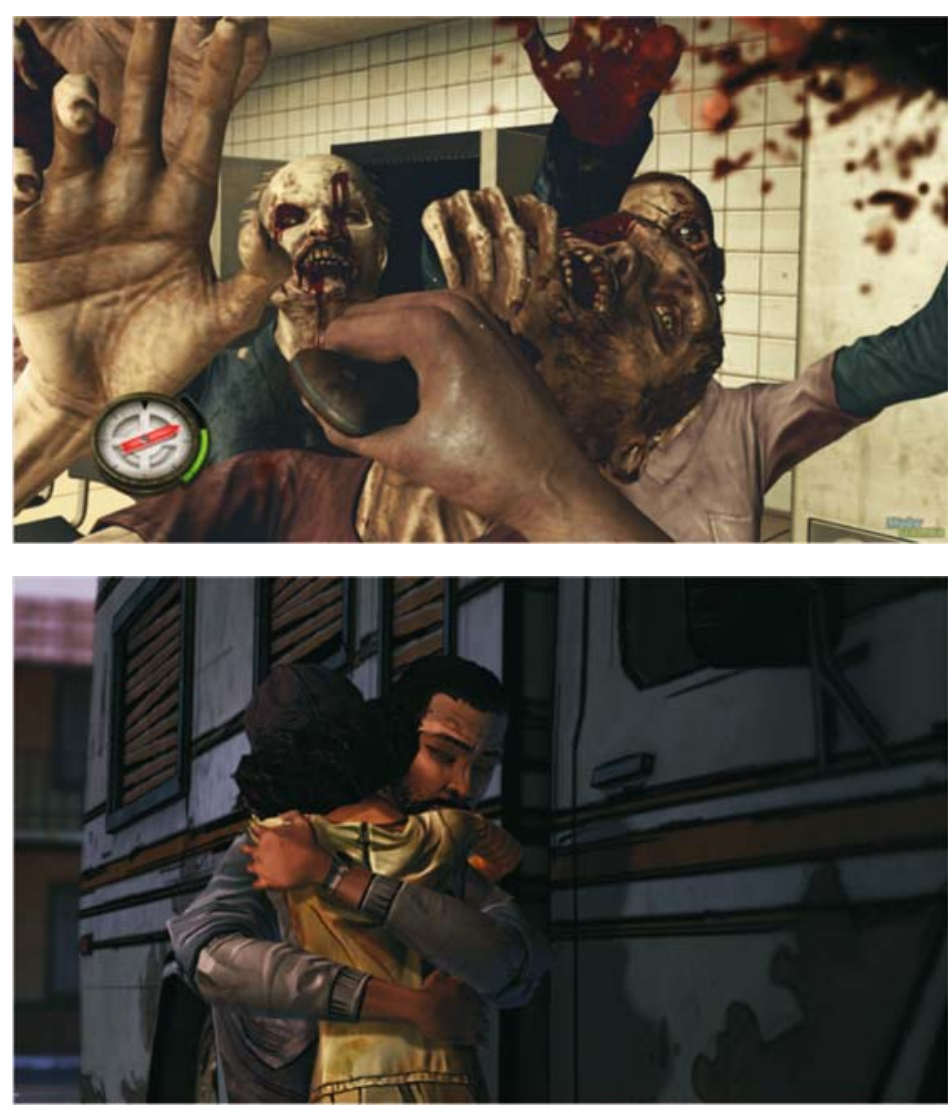